\section{GC}

Revista Nacional de

Gerenciamento de Cidades

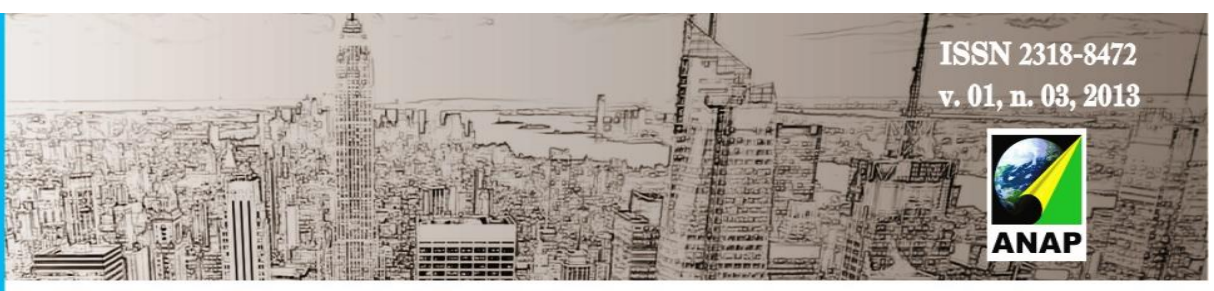

\title{
INTERVENÇÃO URBANA: UMA PROPOSTA DE REQUALIFICAÇÃO DA ANTIGA ESTAÇÃO FERROVIÁRIA DA ESTÂNCIA TURÍSTICA DE TUPÃ
}

\author{
Daniele Grisolia Dualibi ${ }^{1}$
}

\section{Jeane Aparecida Rombi de Godoy Rosin ${ }^{2}$}

RESUMO: Este trabalho tem como objetivo desenvolver uma proposta de requalificação urbana das edificações da antiga Estação Ferroviária, localizada na Estância Turística de Tupã, a qual tem por finalidade implementar novos usos - um centro de educação ambiental. Tendo em vista a importância histórica e arquitetônica do edifício, mediante a necessidade de readequar, revitalizar e valorizar um espaço que está em processo de degradação, considerando sua relevância no processo inicial de urbanização de nossa cidade, torna-se urgente a elaboração de intervenções aptas em contribuir para a vitalidade e urbanidade dessa localidade. Tendo em vista a situação de abandono em que se encontra a antiga Estação Ferroviária, a possibilidade de uma intervenção fundamentada no conceito de requalificação, poderia contribuir não somente para a melhoria de todo o entorno como também para a implantação de equipamentos essenciais as necessidades básicas dos moradores da Zona Sul ao Centro, por meio de uma passarela, um parque linear e centro de educação ambiental.

\footnotetext{
${ }^{1}$ Graduanda em Arquitetura e Urbanismo (FACCAT - Faculdade de Ciências Contábeis e Administração de Tupã - Tupã/SP). E-mail: danidual@hotmail.com

2 Doutoranda no Programa de Pós-Graduação em Arquitetura e Urbanismo na Universidade Presbiteriana Mackenzie/SP. E-mail: jeanerosin@terra.com.br
} 


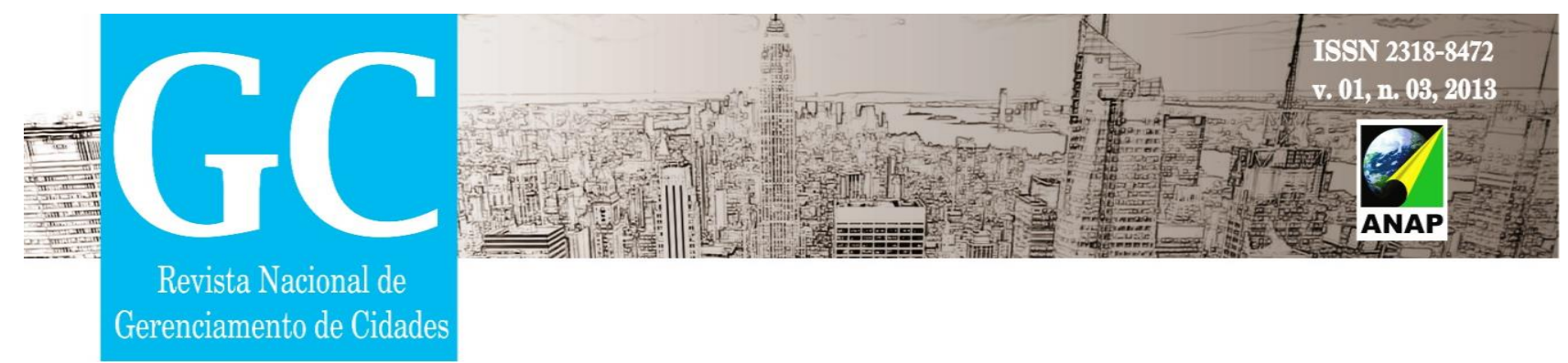

Palavras-chave: Estação Ferroviária. Intervenções Urbanas. Passarela. Parque Linear. Centro de Educação Ambiental. Urbanidade.

\section{INTRODUÇÃO}

Este trabalho tem como objetivo uma proposta de requalificação urbana da antiga Estação Ferroviária da Estância Turística de Tupã, localizada no centro-oeste Paulista, considerando a importância histórica e arquitetônica do edifício, mediante a necessidade de readequar, revitalizar e valorizar um espaço que no passado exerceu grande importância em nossa cidade. Tem ainda a preocupação de alertar as pessoas de uma maneira geral para a necessidade e a viabilidade de reciclar espaços abandonados em locais de convívio, principalmente no que se refere a projetos educacionais, voltados as questões ambientais, a exemplo da possibilidade de implantação de um Centro de Educação Ambiental, os chamados CEAs - uma escola ao ar livre, onde se aprende percebendo e brincando, através das ações educativas contemplando atividades de proteção e recuperação socioambiental ao potencializar a educação para mudanças culturais e sociais, bem como a compreensão da temática "ambiental" em suas diversas dimensões.

A antiga Estação Ferroviária está localizada numa posição estratégica, pois faz parte de uma zona que divide a Zona Sul da cidade onde reside a população de baixa renda, a zona central onde se concentram a população de média renda e equipamentos urbanos destinados a prestação de serviços públicos essenciais, como escolas, hospital, comércio, ambulatórios, dentre outros. Por ocupar uma localização com fluxo intenso desses moradores, e principalmente em razão da precariedade das instalações físicas e deficiências da infraestrutura de seu entorno, atualmente esta localidade se configura como área de recuperação. Ao considerar as diversas vulnerabilidades, fica evidente a necessidade da melhoria de seu entorno, a fim de valorizar e recuperar uma importante área de passagem e que em razão de sua posição, fragmenta um setor importante da 


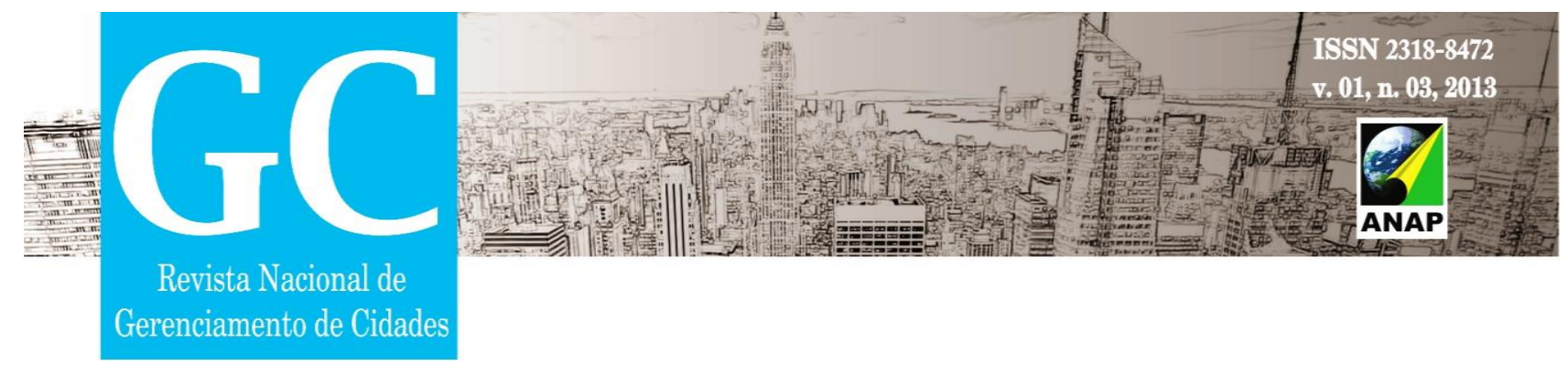

malha urbana. Outro aspecto a ser considerado, refere-se às condições de insegurança existentes, submetendo os moradores desse local a ameaças constantes, mediante a situação de abandono e precariedade, principalmente no período noturno. Diante de tais apontamentos, torna-se oportuno a proposta de requalificação, onde seja contemplado a construção de uma passarela, parque linear e o centro de educação ambiental, visando à melhoria da qualidade de vida dos moradores do entorno imediato, bem como seus usuários, ao possibilitar também novas condições econômicas capazes de gerar um maior desenvolvimento social.

Nesse sentido os espaços urbanos evidenciam em sua artificialidade "a marca que identifica um modo de vida, de habitar, de trabalhar, uma forma de recreação e de deslocação que deixa, no desenho da cidade e em cada época, o retalho da sua utopia". (SOCIEDADE LEIRIÁPOLIS, 2007, p.21).

É com esse fim, que cumprirá ainda um papel essencial na imagem da cidade, fazendo com que a população passe a perceber a relação entre as políticas de conservação integrada, valorizando a memória da cidade e sua vida cotidiana. Assim, a intervenção proposta para essa localidade, para além da restauração do edifício, terá por meio da implantação de centro de educação ambiental, parque linear, proporcionar usos diferenciados voltados para as práticas de valorização do ser humano, sua relação com o meio natural, baseados nos conceitos da conservação e preservação do meio ambiente.

Segundo a Cartilha do ProNEA, o Centro de Educação Ambiental propõe um Programa Nacional de Educação Ambiental que,

[...] tem como eixo orientador a perspectiva da sustentabilidade ambiental na construção de um país de todos. Suas ações destinam-se a assegurar, no âmbito educativo, a interação e a integração equilibradas das múltiplas dimensões da sustentabilidade ambiental ecológica, social, ética, cultural, econômica, espacial e política - ao desenvolvimento do país, buscando o envolvimento e a participação social na proteção, recuperação e melhoria das condições ambientais e de qualidade de vida. (ProNEA, s/a, p.35)

Segundo o MEC, 1994 os CEAs: "Os centros de educação ambiental (...) devem ser, antes de tudo, pólos gestores e geradores de conhecimento, de experimentação 


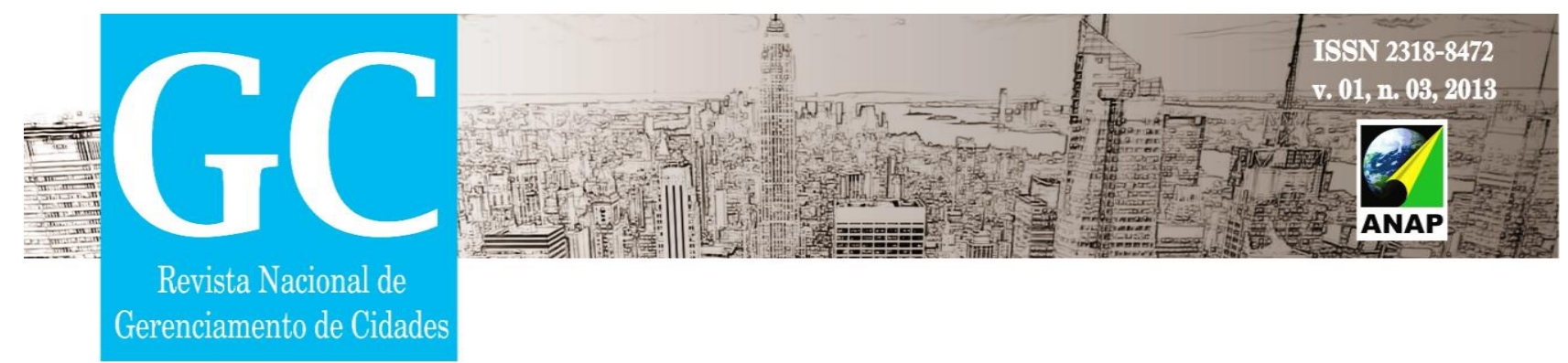

pedagógica e de disseminação e divulgação do conhecimento relativo à questão ambiental" (MEC, 1994, p.7).

De acordo com VIOLA (1997, p. 29),

\begin{abstract}
Durante a segunda metade da década de 80 , o ambientalismo se tornou multissetorializado: começou a penetrar outras áreas e dinâmicas organizacionais, ultrapassou as fronteiras das agências ambientais estatais e das associações e movimentos ambientalistas e passou a impregnar outros movimentos sociais e Organizações Não-Governamentais, universidades, a mídia, agências governamentais não especificamente ambientais e empresas.
\end{abstract}

Os CEAs foram formalizados oficialmente pelo Ministério da Educação e Cultura MEC em 1993, como resultado do I Encontro Nacional de Centros de Educação Ambiental ocorrido em 7 a 9 de dezembro de 1992, realizado na cidade de Foz do Iguaçu - PR.

No final dos anos 70 até meados dos anos 80 algumas iniciativas pioneiras foram impulsionadas, sobretudo pela atuação de pequenas propriedades rurais, ONGs e unidades de conservação, e já no final da década, por empresas privadas de grande porte (sobretudo àquelas ligadas ao setor primário, correspondendo às de mineração, agricultura, floresta, sobretudo).

Na Lei n.9795 de 27/04/1999, o conceito de educação ambiental é entendido a partir de processos através dos quais o indivíduo e a coletividade "constroem valores sociais, conhecimentos, habilidades, atitudes e competências voltadas para a conservação do meio ambiente, bem de uso comum do povo, essencial à qualidade de vida e sua sustentabilidade".

Essa lei também instituiu a Política Nacional de Educação Ambiental, provendo linhas e formas de ação, reconhecendo na esfera legislativa, a importância da inserção da questão ambiental dentro da educação, com o objetivo de conscientizar o desenvolvimento sustentável no Brasil.

Um dos principais objetivos da Educação Ambiental está na compreensão do ser humano em relação a natureza complexa do meio ambiente resultante de suas interações, promovendo assim, uma ação reflexiva e prudente dos recursos naturais, satisfazendo as necessidades da humanidade. A Educação Ambiental deve, assim, favorecer uma 


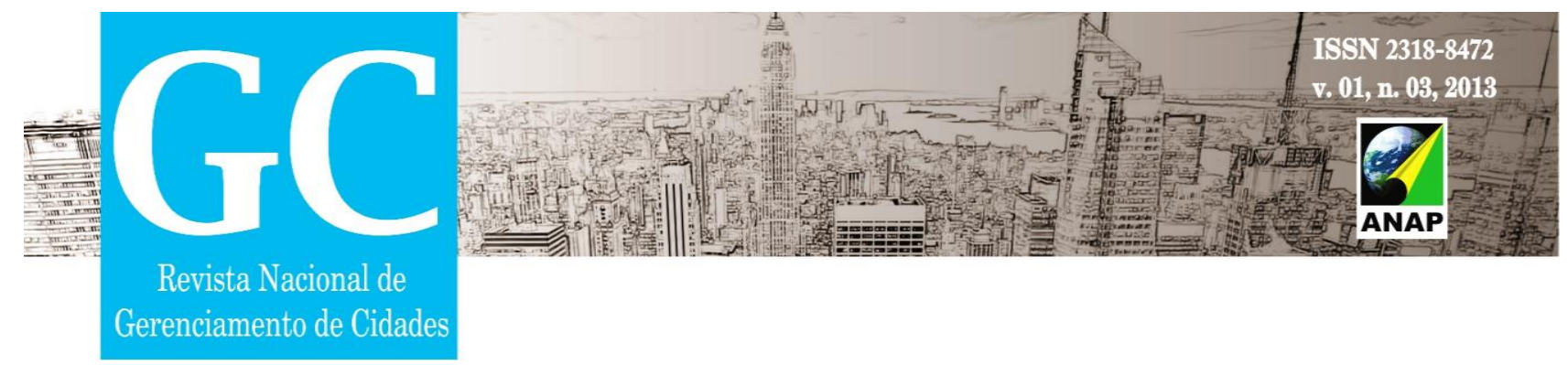

participação responsável nas decisões da melhoria da qualidade do meio natural, social e cultural.

O objetivo principal deste trabalho é propor a requalificação da antiga estação ferroviária da Estância Turística de Tupã, tendo como objetivos específicos consultas e pesquisas nos acervos da história de Tupã, para manter as características do edifício da antiga estação, adequá-las aos novos usos propostos, respeitando as normas de acessibilidade exigida pela ABNT. Recuperar a qualidade desse espaço público que se encontra em situação de abandono, investigando qual a melhor maneira de revitalizar o antigo prédio para adequar a implementação de um centro de educação ambiental, além de possibilitar novos hábitos por meio de atividades relacionadas a eventos culturais, recreativas e de economia, a exemplo da Feira do Verde, além de contribuir para a modernização da Estância Turística de Tupã, por meio de um espaço de uso múltiplo, resgatando assim a vitalidade urbana, através do parque do linear e a passarela melhorando a via de acesso dos moradores da Zona Sul ao Centro. Através do Centro de Educação Ambiental serão promovidos os processos de educação voltados para valores humanistas, conhecimentos, habilidades, atitudes e competências que contribuam para a participação cidadã na construção de sociedades sustentáveis.

Requalificar a antiga estação ferroviária de Tupã- SP terá um papel fundamental no contexto local, melhorando a qualidade de vida de seus moradores e usuários criando também novas condições econômicas capazes de gerar um desenvolvimento local através da oficina de reciclagem e a produção de hortaliças.

Para o embasamento dessa breve estudo, foi realizado levantamento bibliográfico e documental, tendo como fontes sites especializados na temática abordada: teses, dissertações, pois segundo (MARCONI, 2006, p. 44) a pesquisa bibliográfica compreende oito fases distintas: escolha do tema; elaboração do plano de trabalho; identificação; localização; compilação; fichamento; análise e interpretação e redação. Quanto ao material documental foi obtido junto aos acervos existentes no museu, prefeitura e outros órgãos públicos locais; Posteriormente foi realizada a pesquisa de campo, que conforme Marconi 


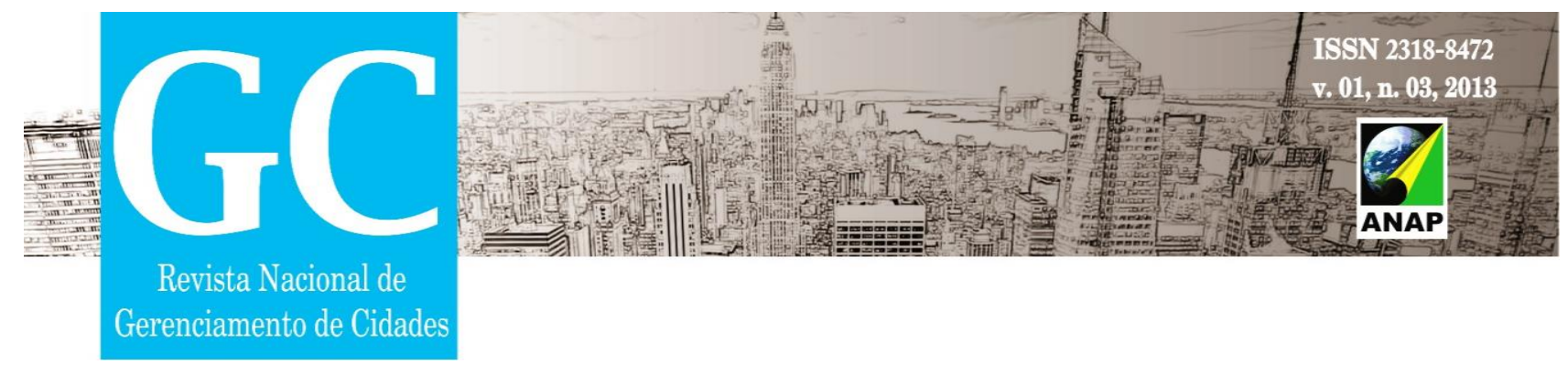

e Lakatos (2002, p. 62) "[...] toda pesquisa implica no levantamento de dados de variadas fontes, quaisquer que sejam os métodos ou técnicas empregados [...]".

Enfim, a coleta de dados válidos e suficientes para a elaboração de uma boa solução de programa de necessidades para alcançar um bom organograma, para que o projeto reflita todos os conceitos a que se propõe.

\section{Terminologia das Intervenções Urbanas}

Ao se tratar de intervenções urbanas o uso adequado das terminologias não deve ser usado de maneira indiscriminada. É preciso que se entenda de maneira clara e objetiva o que cada uma delas realmente significa. Portas (1998), para designar intervenção utilizase de diversos "Re's" em sua explanação:

Conjunto de programas e projetos [...] que incidem sobre os tecidos urbanizados dos aglomerados, sejam antigos ou relativamente recentes, tendo em vista: a sua reestruturação ou revitalização funcional [...]; a sua recuperação ou reabilitação arquitetônica [...]; finalmente a sua reapropriação social e cultural [...]. Mais especificamente trata-se de projetos para intervenções urbanísticas nas quais se faz uso estratégico de recursos culturais tendo por objetivo o desenvolvimento local, e que podem ou não associadas a planos e políticas culturais.

Miles Colean em 1950 criou o termo "renovação urbana", que incluía diferentes programas como "reabilitação", no sentido de transformação em uma malha urbana que esteja fora dos padrões exigidos, "conservação" no sentido de envolver tanto a reabilitação como a demolição para melhorar um local, e o "redesenvolvimento", onde são abrangidas todas as ações de demolição, remoção e reconstrução de toda uma área. O termo renovação urbana foi muito utilizado após a segunda guerra mundial, no período pósguerra, no início da reconstrução das cidades na Europa.

Para Portas (1986, p.94), a renovação se deu através dos arquitetos modernistas e normas da Carta de Atenas, sendo necessária a substituição das estruturas existentes para a adaptação das novas necessidades da vida moderna. 


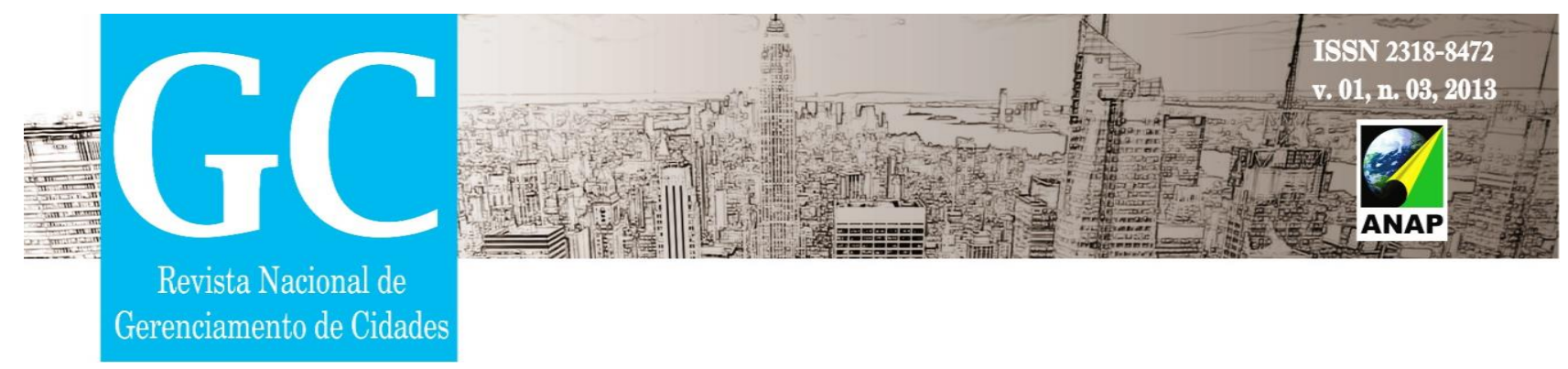

O termo revitalização surgiu em 1960, quando a população deslocou-se dos centros para outras regiões das cidades, acarretando o abandono e degradação nas áreas centrais. Para reverter a situação foram criadas as intervenções urbanas, que tornou-se mais utilizado a partir das primeiras leis de preservação e contextos urbanos, no chamado terceiro movimento de preservação (TIESDEL ET.AL 1996,p 02,04).

Em 1964 a Carta de Veneza amplia o conceito de monumento histórico, que não é mais restrito, mas abrange todo um conceito de acontecimentos históricos. Segundo Schicchi (2005), quando se pretende oferecer nova função e forma às arquiteturas e contextos urbanos constituídos, e que simultaneamente respeite ou incorpore a paisagem existente , os valores históricos e de memória presentes neles. Para Del Rio (1991, p.36),

[...] a requalificação urbana é uma nova postura que se distancia igualmente, tanto dos processos traumáticos de renovação seletiva de áreas desocupadas, preservação de interesse histórico e cultural, reciclagem cuidadosa de usos em imóveis históricos, promoção de novos usos e recuperação ambiental.

A nova tendência das intervenções é a reabilitação, que é um dos termos mais utilizados. Segundo Valentim (2007, p.31), o termo:

\footnotetext{
Reabilitação tem sido empregado por muitos autores como forma de expressar "um modo de intervenção urbana voltada à superação dos passivos ambientais e econômicos resultantes de um histórico de industrialização pouco preocupado com suas externalidades negativas" tendo por meta a reinserção do local no ciclo econômico da cidade e o desenvolvimento urbano sustentado.
}

Requalificação urbana é uma forma de atuação onde o desenho da cidade já está pronto e há um interesse pelo patrimônio histórico e ao processo de desindustrialização das cidades. É uma nova forma de atuação no plano urbano associada a cultura urbana e a capacidade de atração e desenvolvimento sustentável dos territórios, tendo em vista a regeneração dos tecidos físicos e sociais.

\section{Proposta projetual}




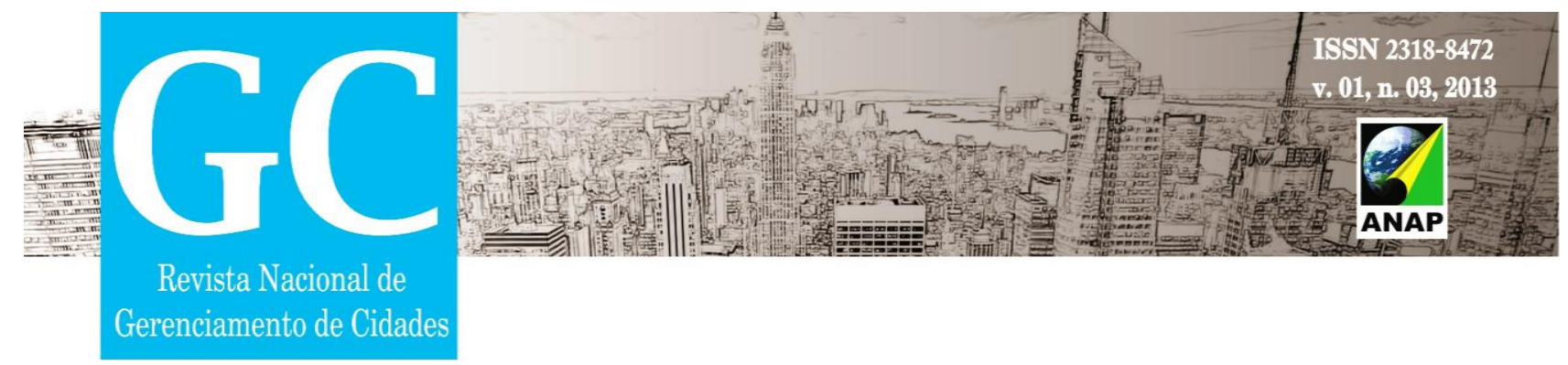

A proposta nasceu da necessidade de uma intervenção urbana diante de um espaço que hoje está em processo de degradação, sem uso e, por ocupar uma localização estratégica na malha urbana. Baseado em pesquisa bibliográfica, e análise de correlatos, foi elaborado um programa de necessidades e um organograma.

Em seguida foi feita a escolha do terreno considerando as diretrizes do plano diretor do município e a partir dessas definições, foi realizado um levantamento "in loco", com detalhamento da topografia do terreno e plantas fornecidas pela SEPLIN de Tupã.

O projeto prioriza a instalação de um Centro de Educação Ambiental, como forma de desenvolver nas crianças e seus familiares a importância das questões ambientais, e também requalificar um espaço urbano que está abandonado com valor histórico significativo à população tupãense, como forma de melhores condições de vida seja no convívio social ou cultural.

Para chegar ao resultado final, foram estudadas diversas soluções criativas de caráter técnico aptas em desenvolver uma utilização saudavel do espaço físico, do mobiliário, e jardins com orientação de profissionais envolvidos com o tema.

O terreno escolhido para a proposta do projeto está localizado no Pátio da Fepasa - KM. 541 ao Km 542+072.50 m. do Trecho Itirapina - Panorama - Município de São Paulo. $O$ antigo barracão está localizado à Rua Tupinambaranas $s / n$, barracão da FEPASA, em frente à Praça Rui Barbosa, na divisa da Zona Sul com o Centro da cidade. Em virtude da Estação está desativada, formou-se um vazio urbano tornando-se um problema na vida dos moradores e de seu entorno, os quais sentem medo e ameaçados pela atual situação de abandono e precariedade. A topografia do terreno é praticamente plana, as curvas de nível têm caída de no máximo 1 metro para oeste. O solo de Tupã é do tipo médio arenoso. Existe uma grande área verde, com pouca vegetação, apenas com grama plantada ao longo da linha, sem a presença de árvores e flores.

A antiga Estação Ferroviária está inserida em uma zona que divide a Zona Sul da cidade (pop. baixa renda) à zona central onde se concentram a população de média renda e equipamentos urbanos destinados à prestação de serviços públicos essenciais: escolas, 


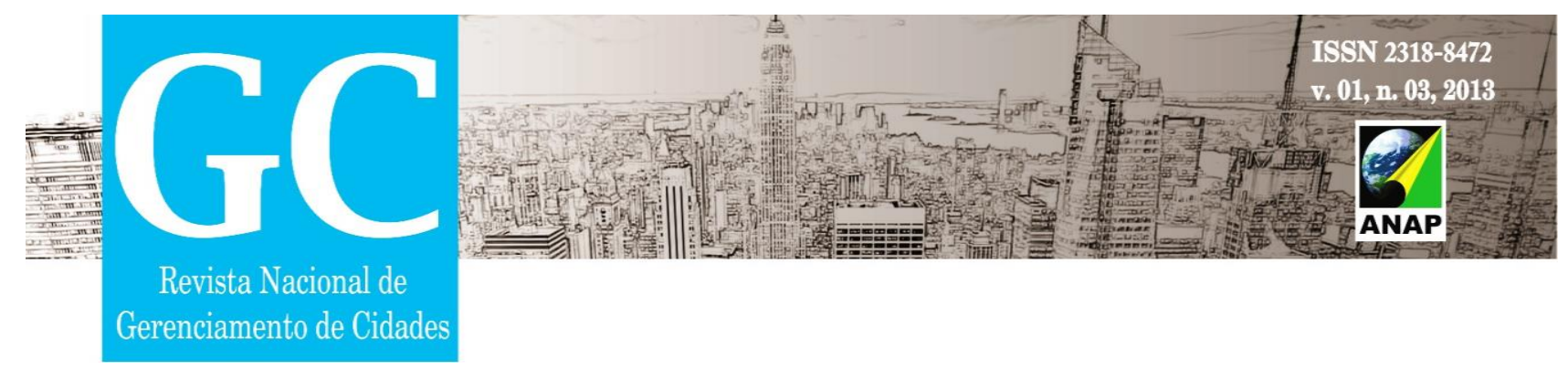

hospital, comércio, ambulatórios, dentre outros. Por ocupar uma localização estratégica, com fluxo intenso da população residente na Zona Sul e principalmente em razão da precariedade das instalações físicas e deficiências da infraestrutura de seu entorno, atualmente esta localidade se configura como área de recuperação, ao considerar as diversas vulnerabilidades de seu entorno imediato.

\section{Conclusões}

Neste trabalho vimos à importância da intervenção urbana, para requalificar um espaço que foi de grande importância para a cidade, com a implantação de um Centro de Educação Ambiental, os chamados CEAs, que tem por objetivo- promover processos de educação ambientais voltados para valores humanistas, conhecimentos, habilidades, atitudes e competências que contribuam para a participação cidadã na construção de sociedades sustentáveis.

Projetos de Intervenção Urbana, podem entre outros aspectos promover melhorias significativas nas condições existentes do edifício da antiga Estação de Trem, assim como adotar metodologias de intervenção onde as reformulações propostas preserve o máximo possível das características arquitetônicas do prédio, visando a implantação de novos usos, principalmente quando a proposta intenciona uma política de inclusão social - Zona Sul com o centro, a fim de possibilitar a toda população melhores oportunidades de lazer, cultura e acesso facilitado e seguro aos benefícios que a cidade pode oferecer - sua urbanidade.

\section{REFERÊNCIAS}

BONBUKI,NABIL.Intervenções Urbanas na Recuperação de Centros Históricos. Programa Monumenta/Iphan/Minc, 2012. 


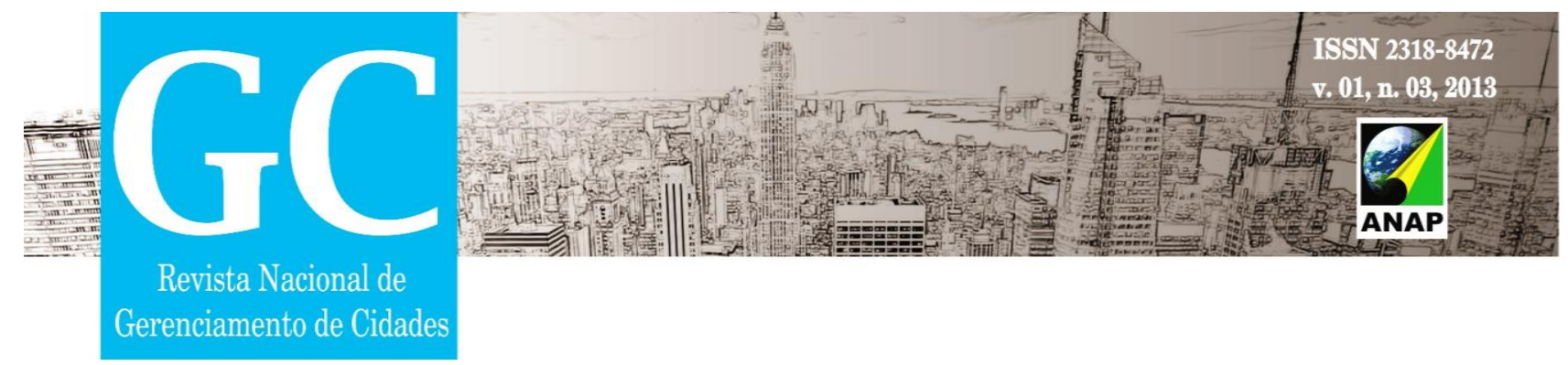

CREA SP, Conselho Regional de Engenharia, Arquitetura e Agronomia do Estado de São Paulo.Patrimônio Histórico: Como e Por que Preservar. $3^{\circ} \mathrm{Ed}, 2008$. Disponível em http://www.brasiliapatrimoniodahumanidade.df.gov.br/acervo/pdf/patrimonio_historico_mp_ sao_paulo.pdf. Acesso em 25 de agosto de 2013.

LEI n.9795 de 27/04/1999 da Educação Ambiental. Disponível em http://www.planalto.gov.br/ccivil_03/leis/19795.htm. Acesso em 21 de agosto de 2013.

LEVANTAMENTO DE SOLOS E INTERPRETAÇÃO

FOTOGRÁFICA DOS PADRÕES DESENVOLVIDOS

EM SOLOS ORIGINADOS DO ARENITO DE BAURU. Disponível em http://www.scielo.br/pdf/sa/v50n1/12.pdf. Acesso em 25 de Setembro de 2013.

MARCONI, M. A.; LAKATOS, E. M. Técnicas de pesquisa. 5ed. São Paulo. Atlas, 2002.

PORTAS, Nuno. Notas sobre a Intervenção na cidade existente. Espaço \& Debates, ANO VI, 1986, n. 17,p.94-104.

PRONEA, Educação Ambiental, $3^{\circ}$ Ed., Brasília 2005. Disponível em http://portal.mec.gov.br/secad/arquivos/pdf/educacaoambiental/pronea3.pdf. Acesso em 23 de agosto de 2013.

SCHICCI, Maria Cristina REstauração, REnovação, REvitalização, REqualificação, REabilitação. Setembro 2005. Disponível em http://www.puccamp.br/centros/ceatec/fau_rev/artigo_002.asp Acesso em 13 de agosto de 2013.

SOCIEDADE LEIRIÁPOLIS (2007) - "Intervenção do Programa Polis em Leiria". Sociedade Leiria Polis, Leiria, p.21. Disponível em http://engenho.info/revista/ed02/dartigos/11-Artigop143-149.pdf. Acesso em 21 de agosto de 2013.

TIESDEL, Steven; TANER, c; HEATH, Tim Revitalizing Historic Urban Quarters. Oxford: Butterworth - Heinemann, 1996. Pág.02-04.

VIOLA, E. "Confronto e Legitimação" In: Ambientalismo no Brasil: passado, presente e futuro. São Paulo: Instituto SocioAmbiental:Secretaria do Meio Ambiente do Estado de São Paulo, 1997, p.29. 